\title{
Pengembangan Desain Tarumpah Dalam Peningkatan Nilai Produk Melalui Pendekatan Estetika Visual
}

\author{
Mochammad Charis Hidayahtullah ${ }^{1}$, Dhika Yuan Yurisma ${ }^{2}$ \\ 1) Desain Produk, Fakultas Desain dan Industri Kreatif, Universitas Dinamika \\ 2) Desain Komunikasi Visual, Fakultas Desain dan Industri Kreatif, Universitas Dinamika \\ Jl. Raya Kedung Baruk 98,60298 \\ Email: charis@dinamika.ac.id, dhika@dinamika.ac.id
}

\begin{abstract}
ABSTRAK
Kesepakatan perdagangan bebas ASEAN Cina (ACFTA) yang mendapat pembebasan biaya masuk di Indonesia berimbas kepada penjualan produk produk tradisional di Indonesia. Penelitian sebelumnya menyatakan bahwa UKM tarumpah Tasikmalaya mengalami penurunan secara penggunaan dan penjualan produknya. Produk tradisional tarumpah disinyalir tidak mampu bersaing dengan produk dari Cina yang murah dengan desain yang modern. Jika keadaan ini terus menerus dibiarkan maka produk tradisional tarumpah Tasikmalaya akan menghilang karena tidak mampu bersaing dengan produk alas kaki yang modern. Urgensi inilah yang menjadi latar belakang untuk melestarikan produk tradisional tarumpah Tasikmalaya kedalam pengembangan desain. Penelitian yang dilakukan menggunakan metode kuantitatif berupa survei konsumen untuk mendapatkan data keinginan konsumen sekarang terhadap produk tarumpah Tasikmalaya. Data keinginan konsumen tersebut diaplikasikan kedalam rekomendasi panduan pengembangan desain dari aspek karakter dan jenis material, aksesoris, warna, dan gaya desain yang konsumen inginkan. Hasil penelitian ini didapatkan bahwa konsumen pria dan wanita di Kota Bandung dengan rentang usia 25-34 tahun menginginkan karakter material yang polos dan bertekstur, material bottom berupa PU Sole aksesoris berupa grafir dan cutting, pengaplikasian warna grayscale dan warna tanah, serta gaya desain yang modern dan edgy untuk tarumpah sandal dan tarumpah jamur, serta gaya desain yang modern dan rumit untuk tarumpah palingpang dan tarumpah palang.
\end{abstract}

Kata kunci: Konsumen, Panduan Desain, Pengembangan, Tarumpah, Tasikmalaya.

\begin{abstract}
The ASEAN-China Free Trade Agreement (ACFTA) which receives entry fees in Indonesia has an impact on sales of traditional products in Indonesia. Previous research stated that Tasikmalaya tarumpah SMEs experienced a decrease in usage and sales. Traditional tarumpah products are allegedly unable to compete with cheap Chinese products with modern designs. If this situation continues, the traditional Tasikmalaya tarumpah products will disappear because they are unable to compete with modern footwear products. This urgency is the background for the traditional products of Tasikmalaya tarumpah into design development. The research was conducted using quantitative methods in the form of consumer surveys to obtain data on current consumer desires for Tasikmalaya tarumpah products. The consumer desire data is applied as a guide for design development recommendations from the aspect of character and type of material, accessories, colors, and design styles desired by consumers. The results of this study found that male and female consumers in the city of Bandung with an age range of 25-34 years want plain and textured material characters, bottom materials in the form of PU Sole accessories in the form of engraving and cutting; application of grayscale and earth colors, and modern design styles and edgy for tarumpah sandals and tarumpah mushrooms, as well as modern and intricate design styles for tarumpah mostpang and tarumpah cross.
\end{abstract}

Keywords: Consumers, Design Guide, Development, Tarumpah, Tasikmalaya..

\section{Pendahuluan}

Alas kaki merupakan produk hasil dari material sebagai pelindung kaki yang terbentuk dari sejarah yang sangat panjang, seiring dengan berkembangnya zaman dan teknologi produk alas kaki tidak hanya sebagai produk fungsional saja, penggunaan alas kaki mulai diasosiasikan dengan fashion, gaya, hingga gender [1] . Penggunaan alas kaki di Nusantara telah dikenal dan tercatat dalam manuskrip Jawa kuno, pada manuskrip tersebut kata sandal (darupa) disebutkan walau hanya sebagian cerita, darupa sendiri merupakan bentuk kata Jawa kuno yang merupakan istilah dari bentuk sandal sederhana yang dinamakan 
tarumpah, penggunaan alas kaki berupa sandal sederhana memang telah dikenal pada pramodern Jawa dan disinyalir sebagai produk alas kaki pertama yang dikenakan oleh masyarakat di wilayah Jawa [2]. Produk alas kaki tradisional tarumpah ini tetap ada, masih diproduksi, dan menjadi produk khas Kota Tasikmalaya. Produk tarumpah yang masih orisinil dan masih ada hingga sekarang ini, yakni tarumpah sandal, tarumpah jamur, tarumpah palingpang, dan tarumpah palang (Gambar 1) [3].

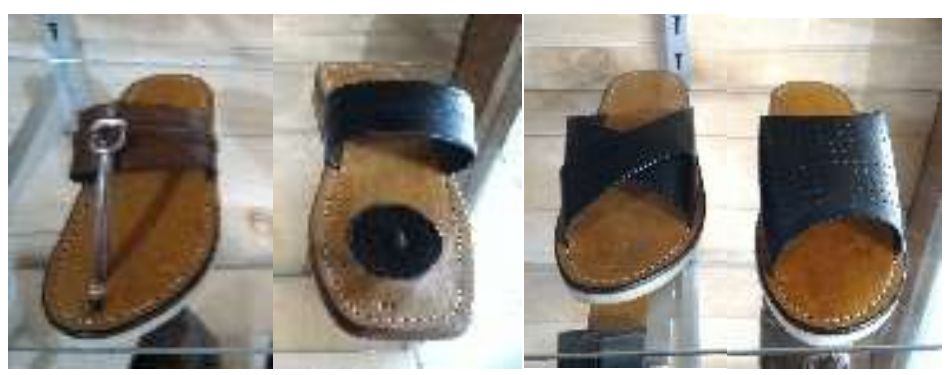

Gambar 1. Tarumpah orisinil khas Tasikmalaya

Alas kaki tradisional terutama produk tarumpah Tasikmalaya mulai berkurang penggunaannya oleh kemunculan produk alas kaki modern, pernyataan ini didapatkan dari hasil wawancara dengan UKM tarumpah Tasikmalaya mengenai penurunan penjualan dan daya minat masyarakat terutama oleh generasi muda [3]. Disisi lain industri alas kaki tetap menjadi strategi perdagangan industri Indonesia, hal tersebut dapat dilihat dari proyeksi McKinsey bahwa tahun 2030, Gross Domestic Product (GDP) Indonesia akan mencapai 4 trilyun rupiah dengan asumsi produk tekstil dan produk alas kaki yang tetap stabil, proyeksi ekspor indonesia pada kedua industri ini akan mencapai 80 milyar USD, oleh karenanya Indonesia memiliki potensi yang besar untuk mengembangan kedua industri tersebut [4].

Tak hanya itu, mengingat bahwa pada tahun 2015 industri kreatif produk fashion terutama industri alas kaki secara langsung menghadapi persaingan yang ketat terutama di pasar dalam negeri oleh produkproduk Cina yang mendapat pembebasan biaya masuk sesuai dengan kesepakatan perdagangan bebas ASEAN-Cina (ACFTA). Jika produk tradisi terutama Tarumpah tidak dikembangkan maka secara berangsur-angsur akan menghilang dikarenakan persaingan produk modern bahkan tidak diminati kembali oleh generasi penerus bangsa ini. Urgensi inilah yang menjadi latar belakang utama untuk dilakukannya sebuah upaya penelitian dalam rangka melestarikan produk tradisi terutama mengembangkan dari aspek desain sehingga dapat diterima oleh masyarakat kembali dan mampu bersaing dengan produk alas kaki modern

\section{Metode Penelitian}

Prosedur pengambilan data penelitian berupa pendekatan kuantitatif berupa survei pasar dengan kuesioner kepada konsumen pria dan wanita di Kota Bandung. Kota Bandung terpilih karena merupakan salah satu kota terbesar di Jawa dengan pertumbuhan perekonomian yang cepat, tak hanya itu kota ini juga dikenal sebagai kota yang menawarkan berbagai macam pilihan pariwisata dari wisata sejarah hingga wisata belanja [5]. Alasan penelitian ini dilakukan pendekatan kuantitatif berupa survei pasar dengan kuesioner adalah karena metode ini dianggap sebagai metode yang tepat karena menghasilkan dan mendapatkan data berupa keinginan pasar dan penilaiannya terhadap produk Tarumpah. Tak hanya itu, selain mudah, ekonomis, dan singkat, survei konsumen sering digunakan untuk memperoleh data keinginan pasar terhadap produk apparelyang diteliti [6].

Keempat jenis tarumpah yang masih orisinil dan tetap ada seperti tarumpah sandal, tarumpah jamur, tarumpah palingpang, dan tarumpah palang ini dinilai oleh sebanyak 64 responden dengan rentang usia 25 hingga 34 tahun di Kota Bandung, responden ini terdiri atas 31 konsumen pria dan 33 konsumen wanita. Ruang lingkup penelitian hanya mencakup desain dan tampilan dari produk terkait dengan tujuan yang sama seperti judul penelitian yakni mendapatkan data panduan untuk pengembangan desainnya.

\section{Hasil dan Pembahasan}

\subsection{Pengembangan Produk Tarumpah}


Pengembangan produk didefinisikan sebagai suatu proses yang secara berturut-turut berdasarkan informasi tertentu. Tahap pengembangan dapat dilakukan melalui analisa hingga komersialisasi, produk yang dikembangkan merupakan produk gagasan baru yang diminta oleh konsumen [7]. Tipe pengembangan produk ada berbagai macam, salah satunya adalah dengan tipe peningkatan dan perbaikan dari produk yang sudah ada [8]. Tipe pengembangan produk tersebut dianggap yang paling cocok untuk diaplikasikan pada tarumpah Tasikmalaya. Pengembangan produk ini akan menawarkan rekomendasi dari aspek selera dan keinginan yang berpengaruh terhadap kepuasan pelanggan yang didasarkan pada survei pasar berupa umpan balik konsumen dari keempat produk tarumpah terkait.

Penelitian ini hanya difokuskan pada penambahan ataupun modifikasi dari produk yang sudah ada dengan tujuan untuk menjaga lini produk tarumpah tetap lestari dan mampu bersaing dengan produk modern. Publikasi penelitian ini hanya menjabarkan fase pengembangan konsep produk yang didasarkan pada kebutuhan pasar sehingga didapatkan rekomendasi panduan pengembangan desain produk tarumpah.

\subsection{Hasil Survei Keinginan Konsumen}

Hasil survei keinginan konsumen merupakan hasil data rekomendasi yang dapat diaplikasikan kedalam pengembangan tarumpah tasikmalaya. Variabel apparel penelitian ini antara lain aksesoris, jenis dan karakter material, tekstur, dan warna yang diinginkan konsumen. Berikut adalah tabel kesimpulan yang didapatkan dari survei keinginan konsumen dari 64 responden konsumen pria dan wanita dengan rentang usia 25 hingga 34 tahun di Kota Bandung:

Tabel 1 Keinginan konsumen dalam pengembangan tampilan tarumpah

\begin{tabular}{lll}
\hline Kriteria & Pria & Wanita \\
\hline Karakter bahan & Polos dan bertekstur & Polos dan bertekstur \\
\hline Aksesoris & Grafir & Cutting \\
\hline Material upper & $\begin{array}{l}\text { Kulit binatang, goretex, } \\
\text { katun }\end{array}$ & $\begin{array}{l}\text { Kulit binatang, goretex, } \\
\text { kulit imitasi }\end{array}$ \\
\hline Material bottom & PUSole & PUSole \\
\hline Jenis warna & Grayscale & Earthone \\
\hline
\end{tabular}

(Sumber : Hasil Survei Pribadi Konsumen Pria dan Wanita usia 25-34 di Kota Bandung, 21 Juli 2017)

Berdasarkan Tabel 1, konsumen pria usia 25-34 tahun menginginkan produk tarumpah dengan karakter material yang polos dan bertekstur, serta modifikasi aksesoris berupa grafir pada materialnya. Jenis materialnya sendiri untuk material upper tarumpah yang diinginkan antara lain kulit binatang, goretex, ataupun kain katun. Sedangkan material bottomnya yang diinginkan adalah material $P U$ Sole. Warna tarumpah yang diinginkan adalah warna-warna yang grayscale. Sedangkan konsumen wanita usia 25-34 tahun menginginkan produk tarumpah dengan karakter material yang sama yakni polos dan bertekstur, namun modifikasi aksesoris berupa cutting pada materialnya. Jenis materialnya sendiri untuk material upper tarumpah yang diinginkan antara lain kulit binatang, goretex, ataupun kulit imitasi. Sedangkan material bottomnya yang diinginkan sama seperti pria, yakni material PU Sole. Warna tarumpah yang diinginkan adalah warna-warna earthone.

\subsection{Hasil Survei Konsumen Mengenai Gaya Desain untuk Pengembangan Tarumpah}

Dibutuhkan juga panduan gaya desain dalam mengembangkan tarumpah sehingga UKM memiliki gambaran dalam memodifikasi gaya desain produknya. Gaya desain ini juga merupakan validasi fase pengembangan produk terhadap tarumpah sehingga didapatkan selera konsumen terhadap gaya desain produk terkait. Responden konsumen pria dan wanita rentang usia 25-34 tahun tersebut memilih kedua produk alas kaki sejenis, yang diantaranya empat jenis tarumpah yang dibandingkan dengan empat produk modern sehingga akan didapatkan kecenderungan selera gaya desain yang dapat diaplikasikan pada pengembangan tarumpah Tasikmalaya. Berikut adalah keterangan kata kunci gaya desain yang dijadikan sebagai perbandingan:

Tabel 2 Sifat gaya desain produk sejenis tarumpah dengan produk modern 


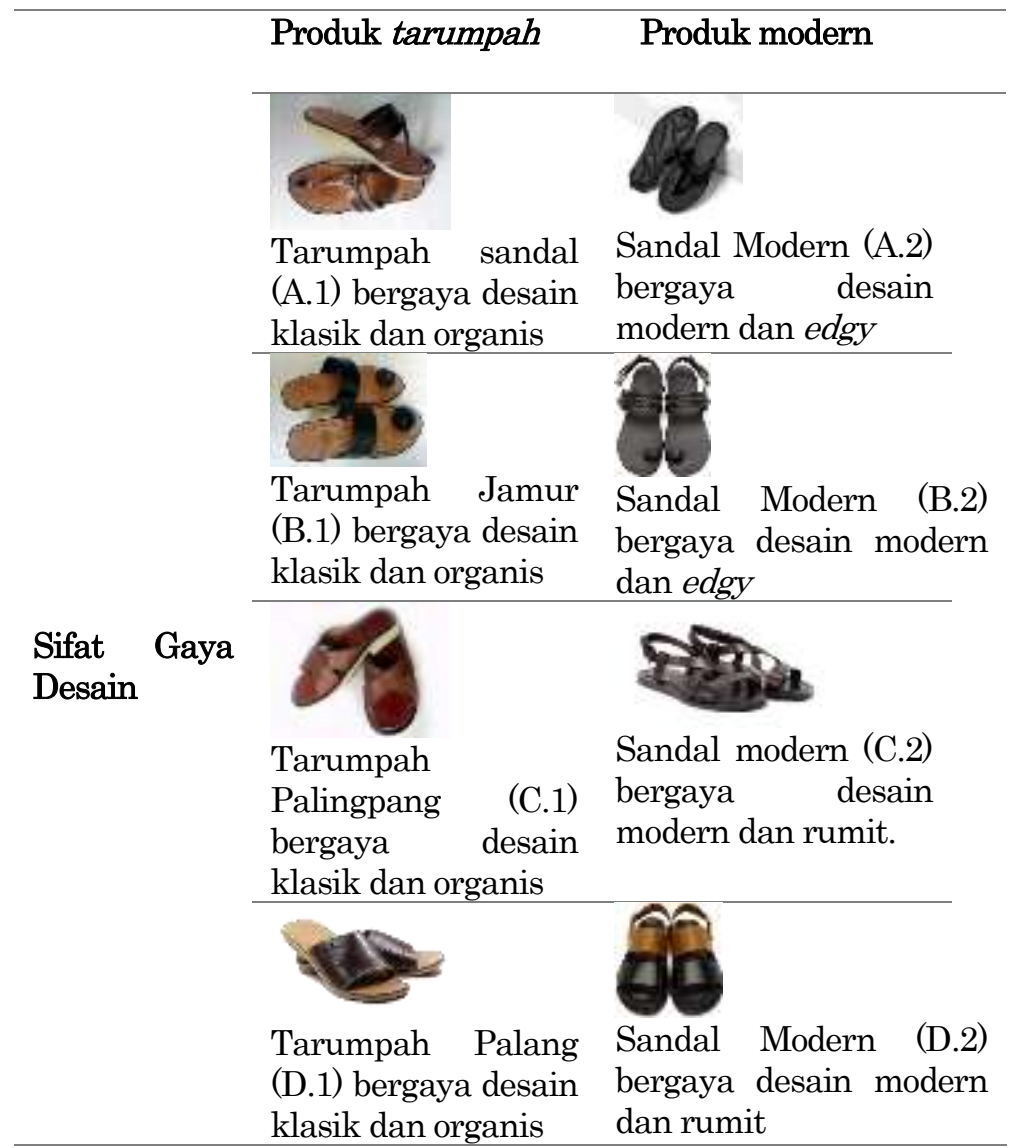

(Sumber : Foto dari berbagai sumber dan kata sifat gaya desain dari analisis Pribadi)

Penilaian tersebut secara langsung membidik selera konsumen pria dan wanita di Bandung untuk lebih memilih Tarumpah Tasikmalaya (A.1 hingga D.1) atau produk modern (A.2 hingga D2), sehingga dari 64 responden didapatkan hasil kesimpulan penilaian mengenai kecenderungan konsumen sebaga berikut:

Tabel 3 Kesimpulan penilaian kecenderungan konsumen terhadap produk tarumpah (A.1-D.1) atau produk modern (A.2-D.2)

\begin{tabular}{lll}
\hline \multicolumn{2}{l}{ Generasi Usia 25-34 Tahun } \\
\hline Variabel & Pria & Wanita \\
\cline { 2 - 3 } & Penilaian & Penilaian \\
\hline Tarumpah Sandal & A.1 $=39 \%$ & A. $1=30 \%$ \\
(A.1) & A.2 $=61 \%$ & A. $2=70 \%$ \\
\hline Tarumpah Jamur & B.1 $=35 \%$ & B. $1=12 \%$ \\
(B.1) & B.2 $=65 \%$ & B. $2=88 \%$ \\
\hline Tarumpah & C. $1=29 \%$ & C. $1=12 \%$ \\
Palingpang(C.1) & C.2 $=71 \%$ & C. $2=88 \%$ \\
\hline Tarumpah Palang & D. $1=38 \%$ & D. $1=15 \%$ \\
(D.1) & D. $2=52 \%$ & D. $2=85 \%$ \\
\hline
\end{tabular}

(Sumber : Analisis Hasil Survei Konsumen Pria dan Wanita usia 25-34 di Kota Bandung, 21 Juli 2017)

Berdasarkan Tabel 2, didapatkan bahwa konsumen pria dan wanita lebih dari setengahnya atau 50\%-nya lebih memilih untuk mengenakan dan membeli produk modern dibandingkan dengan produk tarumpah. Hasil kesimpulan penilaian kecenderungan tersebut dapat ditarik menjadi sebuah kesimpulan berupa kata kunci panduan gaya desain, antara lain modern dan edgy untuk tarumpah sandal dan tarumpah jamur, serta modern dan rumit untuk tarumpah palingpang dan tarumpah palang. 
Tabel 4 Panduan gaya desain konsumen usia 25-34 tahun

\begin{tabular}{lll}
\hline $\begin{array}{l}\text { Panduan Gaya Desain } \\
\text { Usia 25-34 Tahun }\end{array}$ & \\
\hline Variabel & Konsumen Pria & Konsumen Wanita \\
\hline Tarumpah Sandal & Modern, Edgy & Modern, Edgy \\
\hline Tarumpah Jamur & Modern, Edgy & Modern, Edgy \\
\hline Tarumpah & Modern, Rumit & Modern, Rumit \\
Palingpang & & \\
\hline Tarumpah Palang & Modern, Rumit & Modern, Rumit \\
\hline
\end{tabular}

(Sumber : Analisis Hasil Survei Konsumen Pria dan Wanita usia 25-34 di Kota Bandung, 21 Juli 2017)

\subsection{Hasil pengembangan Desain :}

Aksesoris atau ornamen yang diaplikasikan adalah grafir, bagian grafir tersebut dapat dilakukan pengaplikasian stilasi dari motif tekstil yang kontemporer, motif tersebut dapat berbentuk geometris dan tajam agar berkesan edgy. Cara tersebut diaplikasikan pada bagian tepi upper sehingga memiliki kesan bertekstur, ekslusif, dan modern karena generasi dan gender pria ini menyukai yang bertekstur namun tetap terkesan polos. Stilasi grafir yang diaplikasikan hanya pada bagian tepi dari elemen upper agar tetap berkesan sederhana dan juga tetap modern.

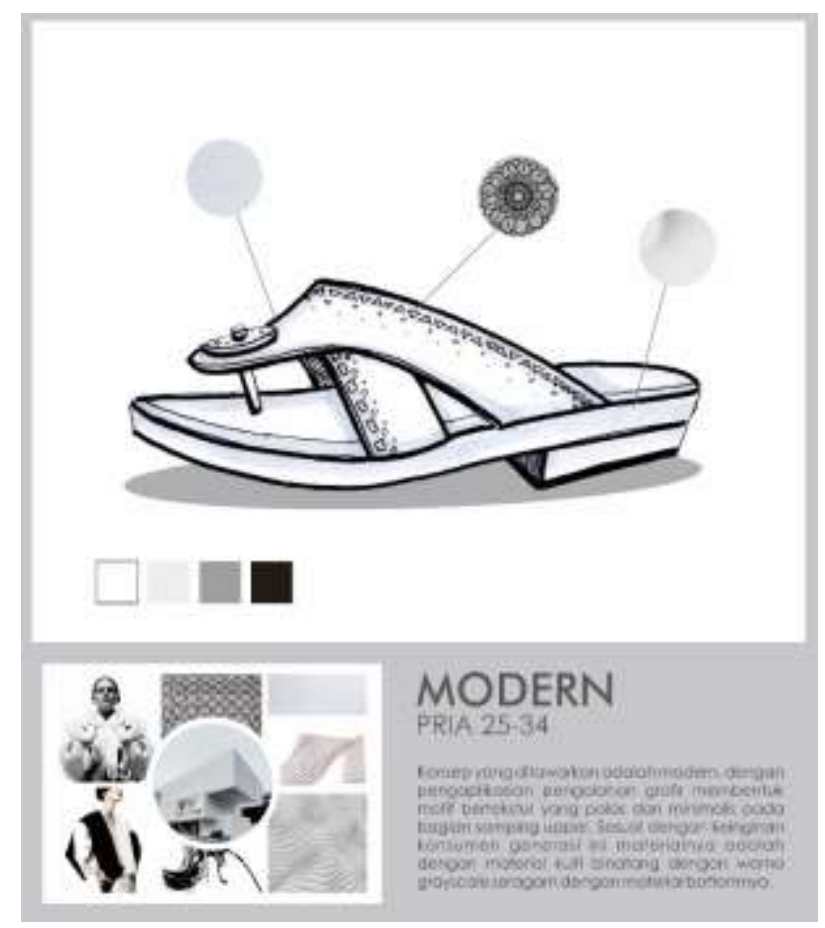

Gambar 2. Desain model pria

(Sumber: Dokumentasi Pribadi, 2017)

Material upper yang diinginkan pria usia 25-34 adalah material kulit binatang. Sedangkan material bottomnya yang diinginkan adalah PU Sole. Warna yang diinginkan adalah warna yang grayscale, untuk itu sebaiknya menggunakan satu warna saja seperti putih ataupun hitam secara keseluruhan agar berkesan modern. Secara desainnya Tarumpah dibuat lebih nyaman dengan pengait yang kokoh, namun kesan tarumpah jamur dengan bulatan pada upper tetap ada dan diaplikasikan agar filosofi dari Tarumpah tidak hilang begitu saja. Pada bagian bulatan berbentuk jamur juga diharapkan jangan dilupakan untuk diberi stilasi grafir dengan motif yang kontemporer sehingga tampak menyatu dengan keseluruhan Tarumpah yang telah dikembangkan. Lebih jelasnya berikut adalah rekomendasi desain diharapkan memenuhi keinginan konsumen terkait, 
Sedangkan sesuai dengan tabel panduan pengembangan pada konsumen dengan generasi 25-34 tahun dengan jenis kelamin wanita memiliki selera dan menyukai produk alas kaki dengan gaya desain yang sama, yakni modern. Aksesoris atau ornamen yang diaplikasikan adalah cutting; bagian cutting tersebut dapat dilakukan dengan terinspirasi tekstil tradisi yang memiliki motif sederhana dan kontemporer sehingga tetap berkesan modern. Pengaplikasian tersebut dapat dilakukan pada salah satu bagian di upper Tarumpah secara penuh sehingga menghasilkan pengembangan desain yang disukai oleh generasi dan gender wanita usia ini, yang menyukai cutting namun tetap terkesan polos dan modern.

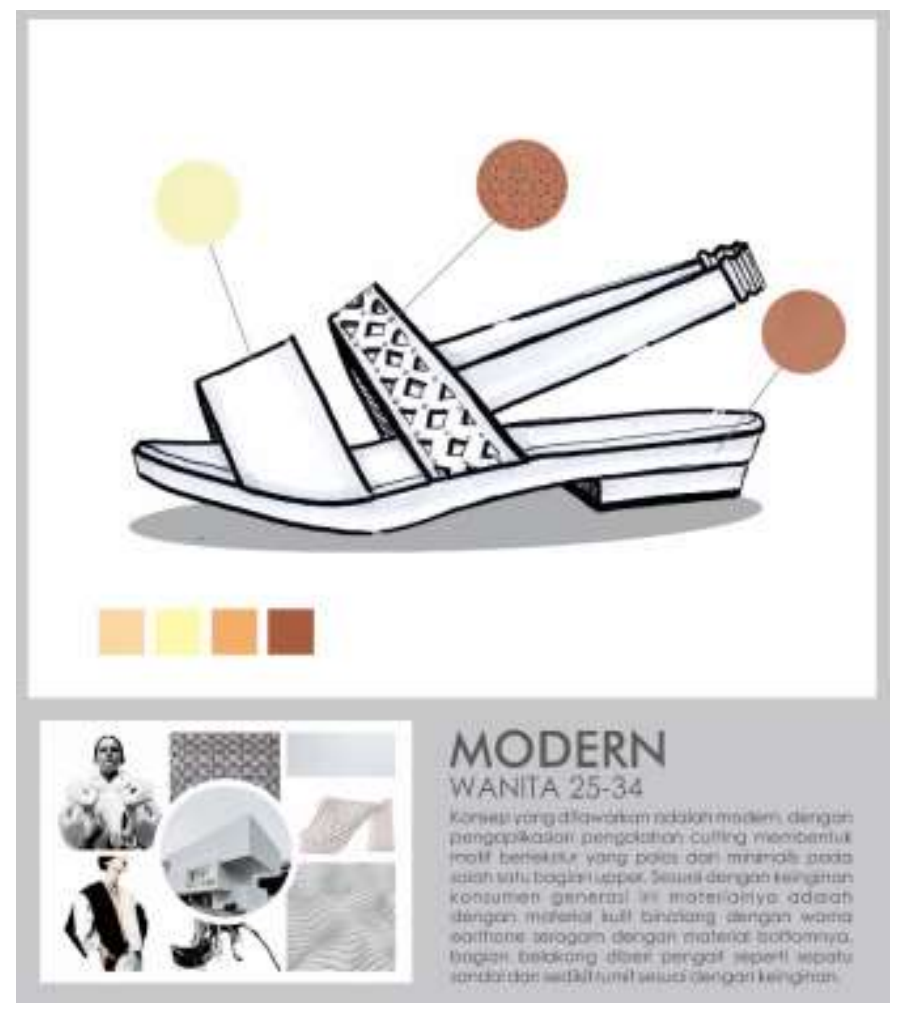

Gambar 2. Desain model pria

(Sumber: Dokumentasi Pribadi, 2017)

Material upper yang diinginkan wanita usia 25-34 adalah material material kulit binatang. Sedangkan material bottomnya yang diinginkan adalah PU Sole. Warna yang diinginkan adalah warna yang earthone, dalam pengaplikasian warna ini sebaiknya menggunakan satu warna atau dua warna saja seperti coklat tua dengan coklat muda, atau keseluruhan coklat muda, sehingga dalam keseluruhan agar berkesan modern karena warna yang diaplikasikan tidak terlalu banyak. Perbaikan produk dapat dilakukan dengan penambahan elemen seperti pengait pada bagian belakang sehingga Tarumpah memiliki bentuk seperti sepatu sandal jika UKM terkait berkenan.:

\section{Simpulan}

Hasil survei pasar mengenai gaya desain dan keinginan konsumen tersebut menjadi rekomendasi panduan dalam pengembangan produk tarumpah Tasikmalaya untuk pangsa pasar konsumen pria dan wanita usia 25-34 tahun di Kota Bandung dan diaplikasikan kepada tahap selanjutnya yakni produksi sampel produk untuk UKM tarumpah Tasikmalaya. Panduan pengembangan tersebut antara lain: Panduan pengembangan produk tarumpah untuk konsumen pria usia 25-34 tahun adalah dengan karakter material yang polos dan bertekstur, serta modifikasi aksesoris berupa grafir pada materialnya. Jenis materialnya sendiri untuk material upper tarumpah yang dapat diaplikasikan sesuai dengan selera konsumen antara lain kulit binatang, goretex, ataupun kain katun, sedangkan material bottomnya adalah material PU Sole. Warna tarumpah yang diinginkan adalah warna-warna yang grayscale. Gaya desain yang diharapkan ada pada produk tarumpah sandal dan tarumpah jamur adalah gaya desain yang modern dan edgy, sedangkan untuk tarumpah palingpang dan tarumpah palang adalah gaya desain yang modern dan rumit. 
Panduan pengembangan produk tarumpah untuk konsumen wanita usia 25-34 tahun adalah dengan karakter material yang sama, yakni polos dan bertekstur, namun modifikasi aksesoris berupa cutting pada materialnya. Jenis materialnya sendiri untuk material upper tarumpah yang diinginkan antara lain kulit binatang, goretex, ataupun kulit imitasi, sedangkan material bottomnya yang diinginkan sama seperti pria, yakni material PU Sole. Warna tarumpah yang diinginkan adalah warna-warna earthone. Gaya desain yang diharapkan ada pada produk tarumpah sandal dan tarumpah jamur adalah gaya desain yang modern dan edgy, sedangkan untuk tarumpah palingpang dan tarumpah palang adalah gaya desain yang modern dan rumit

\section{Daftar Pustaka}

1. Riello, G., \& Mcneil, P., Shoes: A History from Sandals to Sneakers. Bloomsbury Academic, London, 2006. (Book)

2. Jákl, Jiří., Footwear in Premodern Java and Bali, Shoes in History., Pavel Hrubec. (1), Museum of South East Moravia, 9-11, 2014. (Conference Proceeding)

3. Hidayahtullah, M.C., Revitalization of Tradition Javanese Footwear, Icon Arccade., Hafiz Aziz Ahmad and Imam Damar Djati. (1), FSRD Institut Teknologi Bandung, 377-382, 2017. (Conference Proceeding)

4. Bustami, Gusmardi., Indonesia's Textille and Textille Product and Footwear, Kementrian Perdagangan Republik Indonesia, 9

5. Meldarianda, Resti., Pengaruh Store Atmosphere Terhadap Minat Beli Konsumen Pada Resort Café Atmosphere Bandung. Jurnal Bisnis dan Ekonomi Universitas Kristen Maranatha, Bandung, 17(2), 97-108, 2010. (Journal)

6. Kawamura, Yuniya., Doing Research in Fashion and Dress: An Introduction to Qualitative Methods, Berg International Publisher, Oxford, 2011. (Book)

7. Kotler, P., \& Amstrong, G., Principles of Marketing, Prentice Hall Inc, New Jersey, 2011. (Book)

8. Ulrich, K.T., \& Epingger, S.D., Product Design and Development, Mc Graw Hill, New York, 2001. (Book) 
